\title{
From oligos to Oprah—the consumer and biotech
}

\author{
Paul Oestreicher, Tim Warner \& John Mack \\ Until recently, biotech firms did not concern themselves much with the complications of product advertising and \\ corporate brand image-making. A media firm outlines the strengths of direct-to-consumer approaches; an industry \\ commentator counters.
}

ndustry observers assert that the biotech industry will put more products on the market in the coming 10 years than it has done in the past 30 years. Thus, with increasing frequency, the 을 industry will be forced to do something it has never had to do before: promote its products and its companies' image to consumers and healthcare providers.

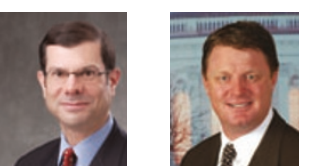

\section{POINT: Biotech needs direct to} consumer communications

Paul Oestreicher \& Tim Warner

Until recently, the biotech industry focused (necessarily) almost exclusively on fundraising, research, clinical trials, manufacturing challenges and regulatory hurdles. All too frequently, companies neglected to insert marketing questions into this mix, questions like-just how are we going to sell this product if it actually works, who are all the stakeholders who can have an impact on the success or failure of our venture, who influences those influencers, and how do I reach them and with what messages? For long-term success, it's important that biotech executives ask and address these questions early on in the biologics development process because finding the right answers is no small task.

Paul Oestreicher is head of the US Healthcare Practice for Hill \& Knowlton, 909 Third Avenue, New York, NY 10022 and Tim Warner leads its Washington, DC-based healthcare team, 607 Fourteenth Street, NW, Suite 300, Washington, DC 20005.

e-mail:paul.oestreicher@hillandknowlton.com ortim.warner@hillandknowlton.com
In the coming years, biotech companies will increasingly find themselves in need of inhouse and agency marketing and advertising talent to produce broadcast and print advertising needed for direct mail, direct-to-consumer (DTC) and direct-to-patient (DTP) communications in the United States and consumerfriendly websites across the globe.

In recent years, both DTC- and DTPdirected campaigns have come under fire from critics who argue that these marketing tools confuse the public, compromise the doctor-patient relationship and play a role in driving up the cost of prescription medicines. We would counter that in a free market for healthcare products, such as the United States, it is the industry's prerogative to educate and orient consumers about its products through judiciously prepared, properly targeted and informative communications. This will be increasingly important for the biotech industry because in the coming years it will have to familiarize consumers with its products as they reach the market at an accelerated pace.

In fact, all indications are that the biotech industry will rely more-as the pharmaceutical industry has-not less, upon DTC-DTP communications to promote medicines not least because biotech products are every bit as complex as pharmaceutical products, if not more so. And in the future, if biogenerics enter the market, there will be additional impetus to capture market share, develop new markets and instill brand loyalty.

Investors are increasingly stating that they have reached the point where they want product sales and profits on a far larger scale to justify their sustained backing over the next ten years. To get from here to there, companies will not only need to inform and educate the consumer and physician about their product's safety and efficacy, but also, obviously, to convince each group to purchase their product. More often than not, biotech companies will find themselves in the very difficult position of trying to create awareness about a novel approach to a disease or medical condition that previously had either gone untreated or had been treated over the years in such a rudimentary or routinely futile way that doctors and patients have grown deeply skeptical about new approaches to healing. We contend that DTC-DTP marketing is an essential strategy to clear hurdles like these.

\section{Tools of the trade now}

Ever since the restriction on DTC advertisements for biopharmaceutical products was lifted in the United States in 1996 by the US Congress and US Food and Drug Administration (FDA), drug companies have embraced it as a marketing tool. The reason is because it works. Biotech products like Genentech's (S. San Francisco, CA, 
USA) Herceptin (trastuzumab), Abbott's (Deerfield, IL, USA) Humira (adalimumab), Amgen's (Thousand Oaks, CA, USA) Enbrel (etanercept) and Neulasta (PEG-filgrastim, granulocyte colony stimulating factor) would not have become so big, so fast without a healthy DTC-DTP component. Certainly, DTC advertising can produce side effects. Creating inappropriate demand can expose large populations to potentially serious or life-threatening side effects. Still, as self-regulatory measures are undertaken by industry under the watchful eye of the FDA, one hopes that such incidents will be exceedingly rare.

A Wall Street Journal/NBC News poll from January $2005^{1}$ found that only $3 \%$ of those surveyed in the United States thought that the pharmaceutical industry was working for the public good and 76\% thought the industry was interested mostly in profits. Biotech executives and scientists need to understand that the public and medical community do not necessarily distinguish between a pharmaceutical and a biotech company. In other words, as the biotech industry matures and starts to move more products into the market, patients and doctors will increasingly scrutinize these products and their manufacturers in the same way as previous products from pharma companies. The pharmaceutical industry has much experience dealing with this scrutiny-biotech companies do not.

One of the best ways for biotechs to address this challenge is to consider DTC-DTP communications at earlier stages in the life cycle of an innovative product. To accomplish this, there are some core fundamentals that must be adopted.

\section{Do it and do it again}

To sell the science that is the basis of new product candidates, adopting a product marketing philosophy is vitally important. The chosen weapon in the past has been the press release and the Internet. In the future, biotechs will need to engage the public and doctors more directly. These efforts do not necessarily need to focus on one specific drug. They must also educate the public about the scientific facts regarding an innovative new area of research that is informing new therapeutic approaches.

Imagine if a multi-year strategic advertising, grassroots, science media, lobbying and science teacher outreach program had been launched to educate the general public and public policy makers regarding the truth about gene therapy, stem cell research, cloning technology or other controversial technologies. Certainly, these technologies would not be nearly as riddled with holes of controversy as they are now. A few television ads here and there may make the industry feel better. But a serious commitment is necessary for extended lengths of time. With this commitment, venture capitalists and other sources of funding may become more confident in the overall viability and potential of scientific research that is perceived to be 'too controversial.'

\section{Keep it simple, not dumb}

No industry inflicts more wounds upon itself owing to poor communication than the healthcare industry. Industry leaders are frustrated that average people do not trust them or understand their motives. At the same time, the industry speaks in complex, multisyllabic language that most college graduates do not understand.

This difficulty in finding a communications common ground conspired against Merck (Whitehouse Station, NJ, USA) in the first trial involving the anti-inflammatory drug, Vioxx (rofecoxib). It was reported that the case was lost well before the conclusion of all the testimony. The science, though compelling in many respects, did not connect with the jury. "We didn't know what the heck they were talking about," juror John Ostrom told The Wall Street Journal.

The language used to explain the scientific foundation of new healthcare products, product candidates or technology platforms must be explained at a reading level designed to empower the general public — the ultimate beneficiaries - to understand. The healthcare industry already has the knowledge and resources to accomplish this, with their own expertise and their ability to tap any of the world's best marketing executives and consulting firms.

Resistance to this notion is virulent within biopharmaceutical corporations, as well as the scientific and medical community. This is rooted in the classic battle of science versus marketing. Many scientists and medical professionals are opposed, or simply don't feel the need, to 'dumb down' their language. It's time to get over it. The mind-set must change. Making the effort to make science more understandable and accessible to the public won't diminish the status of scientists or doctors.

One of the most important challenges regarding biotech DTC is language choice. Thus, science literacy efforts need to work both sides of the problem: ensure language and concepts are presented in coherent, memorable ways while expanding their con- tent and delivery. Getting this right takes on new importance each day as the gap between the volume of information and the public's ability to understand continues to widen.

"We ignore public understanding at our own peril," Eugenie Scott, director of the National Center for Science Education, told The New York Times last August ${ }^{2}$. "People's inability to understand basic scientific concepts undermines their ability to take part in the democratic process," added Jon D. Miller, director of the Center for Biomedical Communications at the Northwestern University Medical School in Chicago.

\section{Speak to future generations}

Healthcare industry leaders must aggressively invest resources to foster a better understanding of its science and technology among future generations. Educating the healthcare consumers of the future will help inoculate the industry and its science from constant attacks from enemies of innovation. What's more, such investment will help create the scientists and researchers that companies and institutions will hire in the future.

There have been many public initiatives to bolster science literacy. And several companies sponsor educational programs in their communities or sections on their website that are useful to children and teachers seeking scientific knowledge. It hasn't been enough-not when poll after poll shows a disgraceful lack of knowledge and deeply ingrained misperceptions.

The dark nexus of poor understanding of science and poor industry reputation is shown by a poll published in the journal Cancer by the American Cancer Society in August 2005 $5^{3}$. More than a quarter of Americans believe that a cure for cancer already exists and the for-profit industry is holding it back.

Biotech companies need to understand that they can't rely upon the government or advocacy groups to educate the public about disease and the research being done to treat it. There is no better way to reach the public and make them aware that progress is being made in the laboratory and in the clinic to treat disease than through the media with DTC marketing.

Simply put, biotech products cannot treat disease and ease suffering unless patients and doctors know they exist, and what they can and cannot do.

1. WSJ/NBC poll. The Wall Street Journal, p. A4 January 21, 2005.

2. The New York Times p. F3 August 30, 2005.

3. Ansler, T. et al. Cancer 104, 653-660 (2005). 


\title{
COUNTERPOINT: biotech needs more than DTC as usual
}

\author{
John Mack
}

There is no doubt that in the coming years, biotech companies will need marketing expertise to complement their R\&D prowess to be successful in the marketplace. Many experts believe that biotech should follow in the footsteps of traditional pharmaceutical companies and adopt direct-to-consumer (DTC) advertising to promote their products to meet this challenge. Most pharma firms now devote roughly $75 \%$ of their DTC budget to TV.

What is good for pharma, however, is not necessarily good for biotech-particularly with respect to DTC TV ads, which are the most common and visible form of product marketing for drug firms. Indeed, DTC broadcast and print advertising (in newspapers and magazines) have become lightening rods for critics who charge that these expenditures are chiefly responsible for the steadily escalating price of 을 prescription drugs in the United States, which threatens to burst the budgets of state and federal government and employers. Critics also say that DTC ads can overstate a product's benefits, oversimplify its side effects. DTC ads potentially compromise the physician-patient relationship because patients may seek advertised drugs over older products that a physician thinks are more suitable for the patient and condition.

\section{DTC can't educate and influence}

Although 30- and 60-second TV ads are effective at reaching a very large audience, they are not effective tools to educate the market about complicated product benefits. TV ads can only scratch the surface of the risks and benefits of pharmaceuticals, and therefore largely fail to provide consumers with sufficient information to make informed decisions. This format is even more unsuitable for informing consumers about the benefits/risks of more complex biologics and targeted therapies, which are biotech staples.

Some advertisers readily admit the inadequacy of broadcast DTC for marketing medicines. The Coalition for Healthcare Communication (an organization representing several ad agencies and health communications companies), for example, asserts that "the primary goal of direct-to-consumer advertising is and should be to convince a consumer to discuss a medical condition with his or her

John Mack is a pharmaceutical marketing expert and industry commentator who pens the pharmaceutical marketing blog (http://www. pharmamarketingblog.com/). e-mail:johnmack@virsci.com doctor. To ask advertising to educate is to ask it something it is not capable of doing."

Advertising agencies are correct in saying that educating the market (consumers and physicians) is key to commercial success. The FDA says, however, that DTC ads do not adequately communicate risk information. Communicating risk is precisely what biotech product advertising — even more so than traditional pharma product advertising - has to do and do well if the industry is to succeed.

Rather than 'dumbing down' the science to fit the narrow DTC advertising format, biotech companies need to master communications channels that allow them the space and interactive tools to explain the science behind the product. After all, ad agencies are quite right that education is vitally important for influencing consumer choice. (I am not saying that biotech needs to educate the general public. In fact, I do not think that biotech companies are wise to do this. Biotechs should leave this task to their trade organization.) As such, biotechs will need to focus on more information-rich and targeted channels such as the Internet, direct mail and other 'out-of-the-box' techniques such as permission-based e-mail marketing and nonbranded disease Web sites. The better these are targeted to patients, the more effective these communication channels will be.

\section{Tailored products, tailored marketing}

Another aspect of broadcast DTC that makes it unsuitable for biotech product marketing is the fact that it cannot be easily targeted to segmented audiences. A biotech can achieve broad segmentation based on cultural and demographic differences through TV, but it's nearly impossible to target patients with a specific disease state or risk factors. The targeted therapies that biotech promises to deliver requires targeted marketing focused on smaller populations of well-defined patients.

Françoise Simon, professor of marketing at the Columbia University Graduate School of Business, and coauthor of the book Building Global Brands: Taking Biotechnology to Market $^{1}$, suggests that biotech-targeted therapy marketing must establish close links with patient advocacy groups and put a greater focus on online communications to reach these targeted patients who, as a rule, are more 'Internetpositive' than the general population.

The patient group for targeted drugs is small, highly motivated and tends to use the Internet for acquiring information on health matters far more than the general population. They also tend to congregate in well-defined 'channels' that are easily targeted by eMarketing (internet/ CDs) techniques. Consequently, biotech marketers can use cost-effective Internet marketing techniques to reach this group more effectively. Biotech sales and marketing personnel also must be trained and organized to accommodate the new targeted branding model, which best suits their products.

\section{You can't have it both ways}

In 2004, the pharmaceutical industry spent somewhere around $\$ 4.5$ billion on DTC advertising $^{2}$. Critics argue that the prices for prescription drugs keep rising in large part because the industry needs to cover the costs of ever-larger expenditures on DTC advertising. According to a Harris poll, the cost of drugs is the main reason why pharma companies are about as popular as tobacco or oil companies these days. The more biotechs spend on DTC advertising, the more the public will correlate the amount spent on marketing with the increase in prices of biotech products.

The challenge for biotech companies in the coming years, more so than for traditional pharma companies, is to develop a marketing strategy that will not negate the innovative, science-based culture of the organization. On the contrary, they must embrace the science that informs its innovative products and find a way not to dumb it down in marketing messages.

The advertising industry says that a 30- to 60 -second TV commercial is more than enough time to convey the simple essential message that "Product X can help solve problem Y, but be mindful of $Z$ side effects." Yet, the biotech industry has long stressed to investors, reporters, doctors and regulators that its products are exceedingly more complex than a pharma product. The industry has used this positioning to justify the high cost of $R \& D$, the enormous time required to translate biomedical science into products and the high consumer price of prescription biologics, which are by and large more expensive than most pharma products. Biotech companies also use this scientific complexity issue as their main argument to dissuade anybody from the notion that generic companies can safely make inexpensive generic biologics.

But you can't have it both ways. Biotech products are either simple to grasp or they are not. If they are complex, and I believe that they are, the marketing efforts to promote them will need to reflect this complexity.

\footnotetext{
1. Simon, F. and Kotler, P. Building Global Biobrands Taking Biotechnology to Market. (Free Pree/Aimon \& Schuster, Inc., New York, 2003).

2. Some Drug Makers Are Starting To Curtail TV Ad Spending. Wall Street Journal May 16, 2005.
} 